\title{
A Rhetorical Analysis of the Discourse of Advertising Herbal Medicine in Southwestern Nigeria
}

\author{
Adeyemi Adegoju (Ile-Ife)
}

\begin{abstract}
This paper examines the persuasive strategies of advertising herbal medicine in southwestern Nigeria. With recourse to the rhetorical model of analysis, the article identifies and discusses the propaganda techniques/rhetorical strategies in the discourse relative to the herbal medical practitioners' ideological perception of trying to project modern-day herbal healing in Africa as an alternative to that of the failing synthetic drugs of western medical practice. Although the social practice of advertising herbal medicine is culturally based, this study reveals that there are no significant culture-specific strategies of advertising in the data sampled, as the communicative strategies generally fit in with the prefabricated style of advertising discourse. In view of the fact that the advertising genre like other areas of public life is a site of struggle over meaning, the study takes a critical look at the instances of the advertisers' tendency to abuse meaning in language by making certain advertising claims which there is no objective evidence to back up.
\end{abstract}

\section{Introduction}

The present researcher grew up in southwestern Nigeria, as an elementary school pupil in the late 1970's, to the consciousness of the advertisement of herbal medicine at strategic locations such as roadsides, markets and motor parks in major towns and cities where the attention of passers-by could easily be attracted. A major channel of reaching the prospective consumers at such settings was the suspension of blaring loudspeakers on the top of stationary vehicles. Although this advertising channel still subsists, a new trend in the advertisement of herbal medicine in modern times is the aggressive marketing drive in both the print and electronic media. Commenting on this, Komolafe (1998: 71) writes:

In recent times, a lot of interest and attention have been drawn to the curative claims and norms (ethics) of Traditional Medicine practitioners in Nigeria. Curative claims by herbalists and Traditional Healers have been headline news in our print and electronic media [...].

This innovation is remarkable in certain respects. First, it resonates with the revival of interest in herbal healing in modern-day health care delivery. Second, the choice of the mass media channels of radio, television and news magazines as opposed to the traditional channel of reaching only a limited number of audiences is a welcome development in the bid to raise the level of awareness on the place of herbal therapy in modern health care delivery. In the light of the foregoing, this study calls attention to a vexed question that has generated so much interest among scholars (cf. van der Geest 1997, Offiong 1999, Olson 2006 and Iroegbu 2006). While these scholars, among others, focus on the place of herbal medicine in basic health services, little or no attention is paid to the rhetorical style of herbal medical practitioners in launching their products. It is against this backdrop that this article examines the deployment of persuasive techniques to launder the image of herbal medical practitioners 
and affirm the efficacy of their products, on the one hand, and to negatively label orthodox medicine and its place in the health care system, on the other hand.

It is useful here to sketch out the rest of the study. After this introduction, we provide information on the data sampled for the study. We then proceed to give an overview of the art of herbal healing. Next, we highlight the rhetorical principles that underpin the study. It is on this note that we go ahead to exploring the rhetorical dynamics of the therapeutic discourse of marketing herbal medicine. Finally, we give the concluding remarks of the study.

\section{The Data}

The data sampled for this study span both the electronic and print media. For the electronic media, we focus on jingles on radio and television. Apart from such jingles, we also consider special programmes where the advertisers buy airtime that covers at least a quarter-hour or a half-hour slot. Such programmes sometimes involve interview sections where the advertisers field questions from presenters and in some cases the advertisers do the talk alone. The jingles and sponsored programmes are drawn from radio and television stations based in the southwestern Yoruba-speaking states of Nigeria. This delimitation is not an attempt to single out the healing culture of a particular ethnic group for discussion or promote it over and above the healing cultures of other ethnic groups in Nigeria. It is noteworthy that the advertisers sampled in this study would rather pride on their products being of African origin than attempting to whip up ethno-cultural sentiments within Nigeria. Thus, the appeal to a larger trans-national (African) identity even in the national news magazines where we have selected paid advertorials clearly sets the tone for the rivalry between traditional African medicine and conventional western medicine. In this regard, Kayode (2006: 44) posits: "Health care systems differ from one society and from one age to the other. The most obvious differences can be observed between the western health care system and the traditional African system."

As to the sample data from the print media, we use select paid adverts in national news magazines - Tell and The News - where the advertisers of herbal medicine seem to have preference for advertising their products. It is interesting to note, however, that there is a considerable degree of overlap between the advertisements across the print and electronic media so much so that focusing on one for analysis would not detract significantly from the patterns of discourse functions which generally characterize the data from the two media. On a final note, we specify the range of the diseases which the herbal medical practitioners claim to have cure for. Such diseases include obesity, diabetes, asthma, arthritis, fibroid and low sperm count. Others are infertility, sexually transmitted diseases (STDs), epilepsy, tuberculosis and prostrate, among others. Having made these basic clarifications, we will have an overview of the art of herbal healing.

\section{Herbal Therapy}

Herbal healing is almost as ancient as history itself, as the knowledge acquired in the field of natural medicine has been passed down through the generations and survive to this day (Morgenstern 2002). Herbal healing is a system of medical treatment in which various parts leaves, barks, roots, seeds, fruit, latex and resin - of different plants are used in order to treat symptoms and promote good health.

Although there are no written records of the origin of herbal practice in Africa south of the Sahara, there are several legends that have been passed down from generation to generation primarily through oral means. Different ethnic groups in Africa have their own legends about the origin of herbal medicine in their own societies. Babalola (2003) draws on a Yoruba legend which explained that the first man to practise the art of herbal healing was Orunmila who was endowed with this knowledge by God. 
The use of herbal medicine has reached an advanced stage in Asia. In China, for instance, herbal treatment has attained a high level of scientific and technological formulation ${ }^{1}$. This is a great challenge to herbal medical practitioners in other parts of the world, especially those in Africa. To this end, Olapade (1998: i) argues:

There has been a global resurgence of interest in Traditional Medicines in the last ten years probably because many of the known synthetic drugs in allopathic medicines for the treatment of various ailments are failing or that the causes of these various diseases are developing resistance to the known drugs.

Little wonder then that a new class of herbal medical practitioners has emerged in Nigeria, professing to be well talented, educated and versatile in formulating and modernizing herbal medicine. They also claim that their activities have been under control and monitoring by relevant bodies such as the Nigeria Natural Medicine Development Agency and National Agency for Food and Drugs Administration and Control. With this background information, we now highlight the basic tenets of the rhetorical theory that underpin our analysis.

\section{Theoretical Model}

Studies in persuasive speaking basically require an exploration of the art of rhetoric. With close reference to the advertising industry, we posit that the principles of rhetoric in persuading the audience to act or think in the desired manner of the advertiser are noteworthy. Thus, we explicate Aristotle's work on rhetoric which was a remarkable departure from earlier works. Such earlier works had neglected the all-important subject matter of proofs and confined themselves chiefly to appeals to the emotions and things irrelevant to the subject. Aristotle's contribution to the art of rhetoric marked a systematic and scientific orientation to the rhetorical theory (Freese 1959).

Aristotle defined rhetoric "as the faculty of discerning the possible means of persuasion". The speech, according to Aristotle, can produce persuasion either through the character of the speaker (ethos), the emotional state of the listener (pathos) or the argument (logos) itself. Rapp (2002) explains that the persuasion is accomplished by character when the speech is delivered in such a way as to render the speaker worthy of credence. He further explains that the success of the persuasive efforts depends on the emotional dispositions of the audience. Thus, the orator has to arouse emotions because emotions have the power to modify our judgements. Finally, the rhetor persuades by the argument itself when he or she demonstrates or seems to demonstrate that something is the case.

Aside from the three means of persuasion, there are three kinds of rhetorical speeches, deliberative, forensic and epideictic. In the deliberative kind of speech, the speaker either advises the audience to do something or warns against doing something. Rapp further explains that accordingly, the audience has to judge things that are going to happen in the future and have to decide whether they will cause advantage or harm. The forensic speech either accuses somebody or defends self or someone. Naturally, this kind of speech treats things that happened in the past. In the final analysis, Rapp (2002) explains that while the deliberative and forensic species have their context in a controversial situation in which the listener has to decide in favour of one or two opposing parties, the third species does not aim at such a decision. The epideictic speech praises or blames somebody, as it tries to describe things or deeds of the respective person as honourable or shameful.

A persuasive speech, we must emphasize, always occurs in a situation where two or more points of view exist. According to Lucas (1992: 309), "there must be a disagreement, or else

\footnotetext{
${ }^{1}$ Cf. http://www.rsc.org/chemistryworld/Issues/2007/May/ChineseMedicineWesternPackaging.asp (accessed January 25, 2008).
} 
there would be no need for persuasion". Given this viewpoint, persuasive speeches centre on four types of arguments or propositions: propositions of fact, value, policy and concern about a problem. O'Hairr et al. (1975: 581-582) explain that propositions of fact assert that something is true or false; propositions of value allege that something is or is not worthwhile; propositions of policy recommend a course of action or policy as necessary and desirable (or unnecessary and undesirable); and the speech designed to create concern about a problem asks an audience to agree that specific conditions should be perceived as a problem requiring solution. We must, however, drop the hint that the classification into these categories is often eclectic as a topic in one category could easily be made to fit into another.

Granted the sensitive and universal nature of the concepts of health, disease and (type of) healing in human life, the propositions or arguments described above predominate the persuader's intent to modify, influence, shape and (if possible) change the beliefs, attitudes and behaviour of the audience as we shall see presently in our discussion.

\section{Discussion}

One of the rhetorical strategies employed in advertising herbal medicine in the discourse is source credibility. The advertisers appear to be credible by displaying practical intelligence and knowledge of herbal healing. While attempting to propagate their credibility, they reel off the symptoms of diseases, while on air, in such a clinical manner that the viewer/listener cannot but marvel at the depth of their erudition. Worthy of note is the way the herbal physicians pontificate, giving the impression that they are well versed in pathology and could, therefore, diagnose the patients' diseases even before interacting with them one-on-one.

This is a rhetorical strategy geared not only at convincing the audience of their competence but also at refuting the perceived opponents or critics of herbal medicine who negatively label herbal medical practitioners as local, shallow and illiterate. In fact, some of the advertisers refute their opponents by claiming that they embark on research activities before formulating their drugs, that they possess certain specialized equipment and other laboratory facilities for diagnosing patients' diseases and that they repackage their products in form of tablets, capsules and syrups. These claims have some rhetorical effects. First, the advertisers seek to emphasize their own methods of herbal healing which are backed by scientific proof and, therefore, have diverged from the traditional methods of herbal preparations such as concoction, decoction, infusion, powder and dried herbs mixed with food. Second, they serve to demystify contemporary herbal healing as being devoid of ritual/occult practices and divination. Finally, the advertisers try to strike a parallel between the practices of herbal healing in Africa with advances in Asian countries like China and India, on the one hand, and with western medicine, on the other hand. This is an example of a parallel case argumentation in which comparisons are drawn between two entities to underscore areas of similarities or dissimilarities.

In order to further make themselves worthy of credence, the advertisers try to appeal to wide geographical spread. Those with limited airtime on radio and television may not be able to read out where all their offices or clinics are located. So, they use such spatial deictic forms as "different locations in Nigeria" or "across the nation", "worldwide", "within Nigeria and overseas". In the news magazine, however, there is the display of plethora of addresses that span major cities and towns in Nigeria. In some cases, some of the advertisers claim to have offices/clinics in London, the United States of America, Switzerland, and so on. Moreover, some claim to have been connected to the global village by displaying their websites on the Internet. All of these claims tend to underscore the herbal practitioners' quest for acceptability. 
Besides the strategies above, the advertisers attempt to establish credibility by answering such appellations as "Dr", "Prince" and "Chief". As regards the use of "Dr", the advertisers try to draw a parallel between themselves and the practitioners of orthodox medicine, particularly in Nigeria, who are identified with the title 'Dr'. The use of this title generally suggests that the bearer is competent in the diagnosis and treatment of ailment. Therefore, the title confers legitimacy on the herbal medical practitioners as specialists that have undergone training in the art of herbal healing and can, therefore, be entrusted with human life. On the contrary, the use of "Chief" and "Prince" in a traditional society has some implications. Chiefs and Princes are supposedly men of honour and integrity who can be entrusted with great responsibilities in society. The rhetorical factor that is brought to bear here is 'character' which is described by Lucas (1992: 326) as "how an audience regards a speaker's sincerity, trustworthiness, and concern for the well-being of the audience".

In some instances, the use of the titles is closely linked to the advertisers' pride in their pedigree in the art of herbal healing. The advertisers usually claim to have inherited the art from their grandfathers or fathers whose healing artistry was extolled as being unrivalled in their days. This is a case of rhetorical appeal to "hereditary endowment" for any trait that is inherited is generally believed to be more enduring than that which is learnt.

All in all, the trail-blazing or landmark efforts that the advertisers claim to have made in their own rights in the bid to chart a new and noble course for herbal therapy is summarized in slogans and catchphrases that are attached to their herbal homes. The following are examples:

Yemkem International: The Pathfinder and Leading Name in Curative Medicine

Ayodele: The Pioneer in African Naturopathic Medicine

Kolaq: The Pacesetter

Rhetorically, the use of the nominals "pathfinder", "pioneer" and "pacesetter" suggests that herbal healing has been transformed and that some personnel is in the vanguard of the innovation. In addition, the use underlines the kind of rivalry that thrives even among the herbal medical practitioners and the attempt made by each of them to project self as "first among equals".

Appeal to motivational proof also serves some rhetorical functions in the discourse. O'Hairr et al. (1975: 585) argues that "at the heart of persuasion is the ability to adapt a message to the feelings, needs, and values of an audience". Advertisers create some needs that the audience would certainly like to meet. In the present discourse, playing on the audience's emotions, especially the desire for things as they used to be is apparent. The advertised herbal product is usually presented as capable of restoring people to their former state of health. This is particularly the hub of the advertisement of herbal medicine when we consider the inevitable transitoriness from sound health to a diseased condition for which the patient would naturally desire healing.

The advertisers' bid to launch herbal medicine as an antidote in restoring normal health, especially where conventional medicine has supposedly failed is interesting. Consider the following excerpts:

Many victims complain of having visited several hospitals and clinics yet could not get cure for their staph. The reason is that they did not use right medication in the first place. Such people use antibiotics and injection which can hardly cure staph aureus but suppresses it because the herbal medicine is the best for it.

(The News, February 14, 2005: 9) 
Herb and root are the best treatment to avoid re-occurrence, [sic] because it cannot be cured with ejection [sic] or any antibiotic only. Because this bacteria's [sic] called staphylococcus have developed resistance to all form of western antibiotics.

(The News, July 25, 2005: 9)

In the above extracts, the advertisers use the "We are different and unique" claim which, according to Schrank, "states that there is nothing else like the product being advertised". Schrank further explains that the claim is supposed to be interpreted as a claim to superiority. Here, the advertisers juxtapose both orthodox healing and herbal healing methods and ascribe a claim of superiority to the efficacy of herbal therapy. This attempt lends credence to the spirited touting of herbal products as 'alternative' therapy to orthodox medicine. This claim brings to bear a dominant propaganda technique in advertisement known as 'compare and contrast' where the viewer/listener is led to believe that one product is better than another although no real proof is given.

One would expect that the present discourse that makes health or safety claims would be supported by competent and reliable scientific evidence that has been evaluated by certain personnel or bodies qualified to review it to prove where, how and why orthodox medicine has failed, on the one hand, and where, how and why herbal healing makes up for the inadequacies, on the other hand. That the advertiser in the first extract above draws on the statements of patients dissatisfied with orthodox medicine - "Many victims complain of having visited several hospitals and clinics yet could not get cure for their staph" - is not sufficient to support a health or safety claim that requires objective evaluation. It must be hinted, at this point, that Nigeria is such a society where people abuse drugs a lot by just walking up to a chemist to buy drugs on self prescription and even when medical assistance is sought, quacks could have been consulted. Statements obtained from such patients would not be sufficient, therefore, to disprove the efficacy of orthodox medicine. The claim that herbal medicine is the best treatment is not convincing moreso that the word "best" belongs to the class of words referred to as 'glittering generalities' commonly used in advertisements. Glittering generalities are important-sounding 'glad words' that have little or no real meaning and when they are used, they demand approval without thinking simply because such an important concept is involved. This takes us to another common propaganda strategy used in advertisements referred to as 'assertion'. An assertion is an enthusiastic and energetic statement presented as a fact, although it is not necessarily true. So, by claiming that herbal therapy is the best without providing evidence for this, the advertisers are using an assertion, in the hope that the subject would simply agree to the statement without searching for additional information or reasoning.

Apart from labeling orthodox medicine negatively, orthodox medical practitioners are also sometimes portrayed in inhuman and unprofessional images by the advertisers of herbal products. Consider this utterance culled from a herbal home's advertisement: "From now on, no doctor can sentence you to death". Naturally, a doctor supports life as a demonstration of his/her human feelings and professional ethics. But since doctors that do not use herbal products supposedly find it difficult to cure certain diseases, the advertisers of herbal products malign them in a most disparaging image of sentencing innocent people to death in the hospital (a place where life should be saved as opposed to a law court where convicted criminals are sentenced to death by the judge). This apparent transposition of actions across divergent fields makes the attack message a forceful one. This is a propaganda technique known as 'name-calling', as negative words are used to create an unfavourable opinion of orthodox medical practitioners in the audience's minds. Meanwhile, the herbal medical practitioners put up a messianic posture in expressions like: "There is permanent cure for your diseases"; "Fibroid. No operations simply take our herbal products"; "All treatments with natural herbs without side effects." These utterances also bring to bear another propaganda 
technique called 'euphoria'. It is the use of an event to generate happiness or euphoria or to boost morale.

In doing so, the advertisers employ the advertising trick called the black/white fallacy. According to Taflinger $\left(1996^{\mathrm{a}}\right)$, a common way in which this trick is used in advertising is by presenting two situations, one with the product and the other without. The one with the product shows circumstances that the advertiser presumes the target audience would like to be in, and vice versa for the situation without the product. For instance, in the above extracts, the situation with the herbal products promises relief from the worries and pains of perceived incurable diseases and gives hope of cure. In particular, the claim that the advertised herbal products have no side effects is not medically convincing. Speaking generally, every drug that is exogenous to the body system has the tendency to cause certain reactions in the system. There have been reported cases of people reacting to 'ordinary' food such as beans and maize, and even vegetables. By genetic variations, there could be some idiosyncratic reactions; what patient $\mathrm{A}$ does not react to may cause adverse reactions in patient $\mathrm{B}$. Therefore, the claim by herbal practitioners that their herbal medicine has no side effects may not be true if the particular drugs about which the statement has been made have not been put to clinical trial and subjected to peer review whereby feedback from patients would be objectively considered. Even the medical parlance 'side effect' among experts is no longer popular, as the expression 'adverse effect' is more scientifically defensible; for every drug has side effect(s) but there are degrees of the effect(s) up to the level to which some could be described as adverse.

Evoking pride in one's origins or cultural heritage is a strand of the motivational strategies in the discourse. The advertised herbal products are usually identified as indigenous African products and they need to be so patronized to affirm the consumer's sense of pride in locally made products. This is a solidarity-engineering technique to bolster up the feeling of ingroupness in the Us (African) group while trying to stir up feelings of disenchantment with the Them (Western) group. Let us consider the following:

It's a new dawn in Africa [...] Times have changed. Africa has come of age. With Ayodele Clinics and the power of African medicine, there are no mysteries about ailments anymore in Africa.

(Tell, August 29, 2005: 15)

Here, there is the use of the propaganda technique of appeal to prejudice, as emotive terms are used to attach value or moral goodness to believing the proposition. The sense of pride evoked here is tied to the origins of the products. In fact, in the extract above, the herbal medical practitioner has to coalesce his own identity (personal) with that of a larger cultural (African) identity for acceptability. The advertising strategy used here is called genetic fallacy. It makes a prediction about something based on where it came from or its origins.

We must, however, be wary of instances of the abuse of this strategy as evident in the following extract:

African ailments are born out of African

problems which need only African solution.

(Tell, March 7, 2005: 17)

The extract above, though found in an advertising discourse, bears a striking semblance of claims in postcolonial writings in African Literature where postcolonial writers strive to debunk Eurocentric universalism which takes for granted both the superiority of what is European or Western, and the inferiority of what is not. Such a statement would then be made in an attempt by the colonized people to find a voice and an identity in an attempt to reclaim their own past and then erode the colonialist ideology by which the past had been devalued. 
However, granted the cross-cultural interactions within the contact zone of the now globalised world, 'cultural polyvalency' would be more beneficial to humanity as opposed to the politics of polarity. This takes us to the concept of 'hybridity', one of the most disputed terms in postcolonial studies. The term 'hybridity' has been most recently associated with Homi Bhabha. In his piece, "Cultural Diversity and Cultural Differences", Bhabha argues that all cultural systems and statements are constructed in what he calls the "third Space of Enunciation" where claims to the inherent purity and originality of cultures are "untenable". Thus, Elizabeth Laragy argues that "Bhabha urges us into this space in an effort to open up the notion of an inter national culture 'not based on exoticism or multi-culturalism of the diversity of cultures, but on the inscription and articulation of culture's hybridity'"2. Thus, claiming that African problems require only African solutions is in furtherance of the racial practice of cultural exclusivity.

With close reference to the argument put forward in the extract in question, there is the error of hasty generalization in lumping together all ailments as African here. Come to think of it, are obesity, hypertension, fibroid, diabetes mellitus, infertility and the like which the advertisers claim to have cure for really African ailments? Medically, it has been proved that ailments which can be said to be truly African are malaria which is commonly found in the tropics and sickle cell anaemia which is typically African by genetic composition. Thus, if these diseases have been specifically mentioned as African ailments and, therefore, African problems for which the herbal medical practitioners are proffering solutions in the African way, the argumentation will be quite valid.

Undoubtedly, it has been discovered that there could be some ailments in the African environment that have proved resistant to synthetic drugs. The success of African Traditional Medicine in such areas where the orthodox medicine has failed has been emphasized by Olapade (1998), Babalola (2005) and Kayode (2006). This is a much-touted opinion in the discourse of advertising traditional medicine in the bid to underlie its place in making up for the so-called inadequacies of orthodox medicine. The way such an argument is generally advanced, however, more often than not tends to discard orthodox medicine as a viable therapy for other ailments. This is an error of attack in propaganda known as 'poisoning the well', where a speaker is so committed to a position that he/she explains away absolutely everything that others offer in opposition.

The way the advertisers stir up nostalgic feelings in the audience is also noteworthy. Consider the following:

Since the dawn of time, man has understood which leaves, fruits, seeds and roots of plants around him were beneficial for the maintenance of health and effective for the remedy of different ailments that he suffers from.

(The News, April 11, 2005: 15)

The trick of advertising here is referred to as argumentum ad vercundium. It is an appeal to tradition and authority in support of some contention. According Taflinger (1996 $)$, the use of the fallacy is suggestive of the popular saying: "As it was in the beginning, is now and ever shall be". This is an appeal to the earliest beginnings to counter Eurocentric claims, for example, that Africa had no past, no (healing) culture and therefore no civilization before the introduction of western (healing) culture.

The place of evidence, that is, information used as logical proof by a persuasive speaker also deserves careful analysis in the discourse of advertising herbal products. According to O'Hairr (1975: 594), "Evidence in whatever form it takes, increases the persuasiveness of a message

${ }^{2}$ Cf. http://www.qub.ac.uk/schools/SchoolofEnglish/imperial/key-concepts/Hybridity.htm (accessed January 25, 2008). 
[...] highly credible evidence sources are more persuasive than less credible sources." For our present purposes, we shall focus on examples, statistics and testimony as forms of evidence.

The use of examples creates vivid images in the minds of receivers. Lucas (1992: 122) argues:

Research has shown that vivid, concrete examples have more impact on listeners' beliefs and actions than any other kind of supporting material. Without examples, ideas seem vague, impersonal, and lifeless. With examples, ideas become specific, personal and lively.

One kind of example recurrent in the discourse is extended example which involves the use of anecdotes. Recounting an anecdote falls under the rhetorical strategy known as 'narration'. Let us consider the following extract:

There have been bizarre cases in our clinics recently which I know no foreign products would have been able to handle. Take for instance a woman who suffered what was diagnosed in the hospital as kidney problem. After a protracted battle using synthetic drugs and those foreign stuffs, the lady was confined to hospital bed ... We gave her some herbal preparations which made her belch and this cleared all the impurities.

(Tell, March 7, 2005: 17)

By presenting this anecdote, the advertiser is able to keep the hope of the audience alive, giving the impression that if others got healed by using the advertiser's herbal products, the audience could also experience the same. Using such an appealing event to boost the morale of the audience, as we pointed out earlier, is a case of the use of 'euphoria'. But we should quickly note that the advertiser may just be saying what would interest the audience in order to sway them. This is because examples are either factual or hypothetical. They are factual if the incidents they refer to really happened, while they are hypothetical when they describe an imaginary situation. In view of the fact that the goals of seeking popularity with the people and achieving specific commercial objectives cannot be completely ruled out in the external world of reality, the anecdote the advertiser uses here could be hypothetical just to defraud the audience. As a matter of fact, one must not gloss over the use of the rhetorical strategy 'absolute certainty' in the expression "[...] which I know no foreign products would have been able to handle" which gives the writer's statement an indisputable air. We have to emphasize the fact that knowledge is relative; what the advertiser claims to know here within the limits of his knowledge and exposure may not be tenable when subjected to further tests.

The advertisers of herbal products also employ testimony. According to Lucas (1992: 135136), we could have expert testimony, that is, testimonies from people who are acknowledged authorities in their fields and peer testimony, that is, opinions of ordinary citizens who have first-hand experience on the subject. We shall consider an excerpt here on expert testimony.

Tens of thousand who have suffered acute obesity, diabetes, rheumatism, high fever, anemia, fibroid, skin disorders, peculiar ailments, etc., have always attested to the efficacy of these drugs which have been certified by NAFDAC.

(Tell, September 5, 2005: 14)

In this testimony, two salient issues are brought to the fore. First, the reference to the numerical strength "tens of thousands" invokes the propaganda technique of 'bandwagon' which is an attempt to persuade the target audience to join in and take the course of action that everyone else is taking. Calling on the audience to join the crowd reinforces people's natural desire to be on the winning side. Thus, crave for herbal therapy is presented here as an irresistible mass movement and it is in the best interest of the audience to join. The use of statistics in the discourse creates a definite rhetorical effect. No doubt, we live in an age of statistics but we must be wary of its use for there is usually more to statistics than meets the eye. Darrel Huff cited by Lucas (1992: 128) argues that although numbers do not lie, they can easily be manipulated and distorted. In the extract above, the advertiser's reference to "tens of 
thousands" who have attested to the efficacy of the advertiser's products sounds rather dubious moreso that there is no way the audience could test or confirm the figure.

Other examples of the ab/use of statistics in the discourse include "Our guarantee is 100\%", "100\% herbal ingredients", and "The medicine will increase sperm count from zero to 85 million". By projecting such staggering figures, the advertiser is trying to give an air of scientific precision that the audience cannot judge for themselves. We have to point out here that the advertisers of herbal medicine seem to borrow the style characteristic of orthodox medical discourse that thrives on scientific proofs based on tests and studies that are statistically driven. But where it can be said in orthodox medical discourse that adequate surveys and tests must have been carried out not just by an individual but in most cases a team of researchers before arriving at statistical data, this cannot be said of herbal medical practice which thrives mainly on idiosyncratic strides, the processes of which are not readily amenable to empirical verification. However, the technique of using statistics here can be linked to the concept of 'intertextuality' which reminds us that each text exists in relation to others. According to Allen (2005: 1):

The fundamental concept of intertextuality is that no text, much as it might like to appear so is original and unique-in-itself; rather it is a tissue of inevitable and to an extent unwitting, references to and quotations from other texts. These in turn condition its meaning; the text is an intervention in a cultural system.

The second interesting issue that their drugs have been certified by the National Agency for Food and Drugs Administration and Control (NAFDAC) needs to be critically examined. It is interesting that most of the advertisers of herbal products claim that their products have been certified by NAFDAC and, therefore, carry NAFDAC REGISTRATION NUMBER - a semiotic label that has become a stereotype in Nigeria's food(drinks) and drugs industries. The word 'stereotype', according to Quasthoff (1978: 3), could mean "something like 'constantly repeated', 'meaningless' with respect to verbal clichés". This is the sense in which we treat the constant NAFDAC REGISTRATION NUMBER in the present situation and in wider national discourse. In this situation, we do not intend to discredit NAFDAC whose achievements under the leadership of Professor Dora Akunyili have been unprecedented:

The achievements of the agency under the dynamic leadership of Akunyili are outstanding and encouraging. NAFDAC is now a household name, as her aggressive crusade against fake, counterfeit drugs and unwholesome processed foods has reached the grassroots. Consumers now scrutinize regulated products for the manufactured, expiry dates and NAFDAC registration numbers.

(The News, August 22, 2005: 9)

It is against this backdrop that manufacturers (not only of herbal products) in Nigeria now attempt to legitimize their products by attaching the ritualistic NAFDAC REGISTRATION NUMBER as the seal of marketability and attendant consumption to them. Although NAFDAC has a directory of certified products, desperate manufacturers could still fake the NAFDAC REGISTRATION NUMBER to deceive the consumers.

Another kind of testimony employed in the discourse is the celebrity testimonial. This is in tandem with the 'Endorsement or Testimonial claim'. According to Schrank, "a celebrity or authority appears in an ad to lend his or her stellar qualities to the product". For example, popular musicians, actors and actresses are used to advertise herbal products. Obesere, a popular Fuji musician in Nigeria, endorsed 'Energy 2000' prepared by Yemkem Herbal Home. What is interesting about the use of this claim is that the celebrities usually claim to use the product but we know very often they do not. The reality of the situation is pictured by Lucas (1992: 139) that the celebrities must have been paid "large sums of money to be photographed with the product in hopes that their popularity will rub off on the product". 
The perceived status of the celebrities and the kind of environments/settings where they are photographed serve some rhetorical functions. In the advertisements, especially on television, men dress corporately in shirt, tie and suit while women dress corporately as well in skirt(suit) and blouse/shirt or in trendy native wears. To complement all of these, the setting or environment where they interact is usually a banking hall or an office space. The dress code and the setting are semiotically deployed to give the impression that herbal products are not consumed by only rural dwellers; the elite in the cities also use them.

On a final note, the deployment of temporal deictic forms in the discourse is rhetorically compelling. Consider the following:

From now on no doctor can sentence you to death.

Time past, it was unending confinement to hospital bed ... But now times have changed.

... Get ready for a unique experience of the power of African

medicine as never before.

It's a new dawn in African medicine.

(underlining mine)

All of these underlined expressions and others such as "before", "now", and "over the ages", are used to capture the transitional phases in the development of African medicine, on the one hand, and the supposed displacement of orthodox medicine by herbal therapy, on the other hand. Time, therefore, becomes an important variable in the discourse. In some cases, advertisers seem to abuse such temporal deictic forms while attempting to underscore the efficacy of their products. The following examples will suffice:

Lose $10 \mathrm{~kg}$ in five days.

Treatment for diabetes under one month.

Penis enlargement within one month.

We have herbal supplement that reduces blood sugar in two weeks.

Gonorrhea: This disease is cured within 24 hours with our herbal solution.

Increase in sperm count could be attained within 72 hours after proper medication has been administered.

Given the amazingly short time frame within which the advertisers promise to heal diseases and the attendant tone of finality even when the state of the patient has not been determined, we are compelled to call attention to the exaggerative power of the advertisers in the discourse. Thus, we comment on the role of hyperbole as a pragmatic strategy in advertising herbal products. Leech (1983: 145) explains that hyperbole 'refers to a case where the speaker's description is stronger than is warranted by the state of AFFAIRS DESCRIBED [...]' To Swartz (1976: 101) "[...] hyperbole provides a means of focusing on specific aspects of reality (whether social or physical) in such a way as to bring about awareness of values and norms associated with those aspects in an emotionally charged way."

The use of hyperbole would normally violate the maxim of 'quantity' in Grice's cooperative principle. According to Grice (1975), the category of Quantity relates to the quantity of information to be provided and under it fall the following maxims:

1. Make your contribution as informative as is required (for the current purposes of the exchange).

2. Do not make your contribution more informative than is required.

(Grice 1975: 45)

As seen in the way herbal medical practitioners advertise their products, they flout the maxim of quantity by sounding rather hyperbolic in their claims. This lends credence to Komolafe's (1998: 71) view: "In a state of professional anxiety and insecurity, the Traditional Healers ignorantly and at times intentionally make sensational or headline news with wrong unproven 
claims of curative ability." This is why critics of herbal medicine have descended heavily on the practitioners that they sometimes claim feats beyond their capabilities, a disposition that can make the unwary patient complacent until more damage is done. Giving herbal practitioners a hard knock, the critics see some of them as charlatans who do not have knowledge of effective treatments they claim they can cure (Danesi 1998).

\section{Concluding Comments}

We have hitherto examined the persuasive techniques employed by medical practitioners in advertising their products. The discussion focuses on the deployment of propaganda techniques such as bandwagon, testimonials, assertion, euphoria, and narration, among others. Besides, the discussion touched on certain rhetorical strategies that make the characters worthy of confidence, and also appeal to the emotions of the audience. Generally, the discussion reveals that the discourse dwells essentially on the four types of arguments or propositions we highlighted at the outset. In the main, the advertisements reflect a general description of a state of affairs in which health matters have truth value (proposition of fact) though ridden with controversial issues. In doing so, herbal healing and orthodox medical practice are evaluated (proposition of value) and the advertisers consider the so-called inadequacies of orthodox medical practice a problem requiring solution (concern about a problem). This informs the projection of herbal therapy as alternative therapy to orthodox medicine (proposition of policy). In advancing these arguments, however, the advertisers have largely engaged in marketing hype. It is interesting that herbal medical practitioners never present their products as those that can control, manage or suppress (symptoms of) diseases. It is permanent cure all the way! Besides, their products are never presented to the consumers as having any side effects. There is, therefore, the overriding effect of the rhetorical strategy of 'absolute certainty' that pervades the discourse. On the contrary, the advertisers embark on the spirited effort at challenging the efficacy of western medicine, thereby creating discontentment with the conventional products that the audience already knows.

\section{References}

\section{Primary Sources}

Tell, No. 10, March 7, 2005.

Tell, No. 35, August 29, 2005.

Tell, No. 36, September 5, 2005.

The News, Vol. 24, No. 06, February 14, 2005.

The News, Vol. 24, No. 14, April 11, 2005.

The News, Vol. 25, No. 03, July 25, 2005.

The News, Vol. 25, No. 07, August 22, 2005.

\section{Secondary Sources}

Allen, Graham (2005): "Intertextuality". The Literary Encyclopedia. http://www.litencyc.com/php/stopics.php?rec=true \&UID=1229 (accessed October 30, 2007).

Aristotle (1926/1959): The "Art" of Rhetoric. With an English Translation by John Henry Freese. Cambridge.

Babalola, Olufemi Emmanuel (2003): "The Relevance of Herbal Medicine to the Practice of African Traditional Religion, Islam and Christianity in Yoruba Land". Ekpoma Journal of Religious Studies 5, 1: 103-110.

Babalola, Olufemi Emmanuel (2005): "The Scientific Basis of African Traditional Medicine. The Yoruba Example". Ekpoma Journal of Religious Studies 6, 1 \& 2. 
Butler, Christopher S. (1989): "Systemic Models. Unity Diversity and Change". Word 40, $1 \&$ 2: $1-35$.

Danesi, Mustapha A. (1998): "Traditional Medicine in Africa". In: Oluwole, Sophie B./Faluyi, Kehinde (eds.): The Essentials of African Studies. Vol. 2. Lagos: 143-163.

Davis, H. H./Walton, P. A. (1977): "News Ideology. Neutrality and Naturalism". Papers in Linguistics 10: 313-339.

Grice, Herbert Paul (1975): "Logic and Conservation". In: Cole, Peter/Morgan, Jerry L. (eds.): Syntax and Semantics. Vol. 3: Speech Acts. New York: 41-58.

Iroegbu, P. (2006): "Harvesting Knowledge of Herbal Resources and Development of Practitioners in Nigeria". Indilinga: African Journal of Indigenous Knowledge Systems 5, 1: 32-50. http://www.ajol.info/viewarticle.php?jid=160\&id=30459 (accessed June 11, 2007).

Kayode, Jimi (2006): "Health Care Communication and Culture of Selected Ethnic Groups in Nigeria". Africa Journalism and Communication Review (AJCR) 1, 1: 43-68.

Komolafe, Kolawole (1998): "Curative Claims and Norms of Traditional Healers in Nigeria". In: Olapade, Ebenezer O. (ed.) (1998): Traditional Medicine in Nigeria. Proceedings of the Seminar Organized by the German Cultural Centre, Goethe-Institut, Victoria Island, Lagos: 71-75.

Laragy, Elizabeth (n.d.): Hybridity. http://www.qub.ac.uk/schools/SchoolofEnglish/imperial/ key-concepts/Hybridity.htm (accessed November 2, 2007).

Leech, Geoffrey N. (1983): Principles of Pragmatics. London.

Lucas, Stephen E. (1992): The Art of Public Speaking. New York.

Morgenstern, Kat (2002): Healing Our Bodies. Healing the Earth. http://www.sacredearth. com/ethnobotany/medicines/Medicine.php (accessed July 30, 2007).

Offiong, Daniel A. (1999): "Traditional Healers in the Nigerian Health Care Delivery System and the Debate over Integrating Traditional and Scientific Medicine". Anthropological Quarterly 72, 3: 118-130. http://www.jstor.org/view/0035491/ap000187/00a0003010 (accessed June 6, 2007).

O'Hairr, Dan et al. (1995): Competent Communication. New York.

Olapade, Ebenezer O. (1998): "Preface". In: Olapade, Ebenezer O. (ed.): Traditional Medicine in Nigeria. Proceedings of the Seminar Organized by the German Cultural Centre, Goethe-Institut, Victoria Island, Lagos: i.

Olson, Jessica (2006): Integrate for Efficiency. Traditional Yoruba Medicine in Nigeria. http://www.coloradocollege.edu/academics/FYE/essays/jolsonfall2006.pdf (accessed May 27, 2007).

Quasthoff, Uta (1978): "The Uses of Stereotype in Everyday Argument". Journal of Pragmatics 2, 1: 1-48.

Rapp, Christof (2002): "Aristotle's Rhetoric". Stanford Encyclopedia of Philosophy. http://plato.stanford.edu/entries/aristotle-rhetoric/ (accessed March 20, 2007).

Schrank, Jeffrey (n.d.): Handout. The Language of Advertising Claims. http://home.olemiss.edu/ egjbp/comp/ad-claims.html (accessed June 15, 2007).

Swartz, Marc J. (1976): "Hyperbole, Politics and Potent Specification. The Political Uses of a Figure of Speech". In: O'Barr, William/O'Barr, Jean F. (eds.) (1976): Language and Politics. The Hague: 101-116.

Taflinger, Richard. F. $\left(1996^{\mathrm{a}}\right)$ : The Power of Words. Advertising Tricks of the Trade. Part One of a Two Part Series. http://www.wsu.edu:8080/ taflinge/tricks.html (accessed February 10, 2007).

Taflinger, Richard. F. $\left(1996^{\mathrm{b}}\right)$ : Words. Further Advertising Tricks of the Trade. Part Two of a Two Part Series. http://www.wsu.edu:8080/ taflinge/tricks.html (accessed June 2, 2007). 
Van der Geest, Sjaak (1997): "Is there a Role for Traditional Medicine in Basic Health Services in Africa? A Plea for Community Perspective". Journal of Tropical Medicine \& International Health 2, 9: 903-911.

http://www.blackwell-synergy.com/doi/abs/10.1046/j.1365-3156.1997.d01-410.x (accessed August 17, 2007).

Melton, Lisa (2007): "Chinese Medicine in Western Packaging". Chemistry World May 2007. http://www.rsc.org/images/Chinese\%20medicine\%20in\%20western\%20packaging_tcm1886531.pdf (accessed August 11, 2007). 